\title{
Penduga Konsisten dari Fungsi Sebaran dan Fungsi Kepekatan Peluang Waktu Tunggu Proses Poisson Periodik
}

\author{
Fatimah Azzahra ${ }^{*}$, I Wayan Mangku² \\ 1 Jurusan Ilmu Aktuaria, Fakultas Sains dan Teknologi, Universitas Binawan, \\ Jl. Raya Kalibata No.25, RT.9/RW.5, Cawang, Kramat Jati, East Jakarta City, Jakarta 13630, Indonesia \\ ${ }^{2}$ Departemen Matematika, Fakultas MIPA, IPB University, \\ Jl. Meranti, Kampus IPB Dramaga Bogor 16680, Jawa Barat, Indonesia \\ *Penulis Korespondensi. Email: fatimah.azzahra@binawan.ac.id
}

\begin{abstract}
ABSTRAK
Penduga yang konsisten dari fungsi distribusi dan fungsi kepekatan peluang waktu tunggu dari proses Poisson periodik dibahas dalam artikel ini. Tidak ada asumsi bentuk parametrik tertentu dari fungsi intensitas proses Poisson periodik. Situasi dipertimbangkan ketika hanya ada realisasi tunggal dari proses Poisson periodik yang teramati dalam interval terbatas $[0, n]$. Hasil pembuktian menunjukkan bahwa penduga yang diusulkan konsisten ketika $n \rightarrow$ $\infty$.
\end{abstract}

\section{Kata Kunci:}

Proses Poisson; Kepekatan; Waktu Tunggu; Penduga Konsisten

\section{ABSTRACT}

The consistent estimator of the distribution and the density functions of the waiting time of a cyclic Poisson process is considered and investigated. We do not assume any particular parametric form of the intensity function of the cyclic Poisson process. We consider the situation when there is only a single realization of the cyclic Poisson process is spotted in a bounded interval $[0, n]$. We proved that the propose estimators are consistent as $n \rightarrow \infty$.

Keywords:

Poisson Process; Density; Waiting Time; Consistent Estimation

Format Sitasi:

F. Azzahra and I.W. Mangku, "Penduga Konsisten dari Fungsi Sebaran dan Fungsi Kepekatan Peluang Waktu Tunggu Proses Poisson Periodik," Jambura J. Math., vol. 3, no. 2, pp.128-139, 2021

\section{Pendahuluan}

Proses stokastik adalah sebuah proses yang menggambarkan kejadian-kejadian yang terjadi secara acak dan berubah seiring dengan berjalannya waktu. Proses Poisson adalah salah satu proses stokastik dengan waktu kontinu. Proses Poisson merupakan proses pencacahan dimana banyak kejadian pada interval waktu terdistribusi Poisson. Proses Poisson dapat dibedakan menjadi proses Poisson homogen yang fungsi 
intensitasnya merupakan fungsi konstan dan proses Poisson nonhomogen yang fungsi intensitasnya bergantung pada waktu [1]. Salah satu contoh proses Poisson nonhomogen adalah proses Poisson dengan fungsi intensitas berupa fungsi periodik.

Serangkaian proses dikatakan periodik jika setelah suatu satuan waktu proses tersebut cenderung berulang. Suatu periode dapat berupa harian, mingguan, tahunan, atau dalam bentuk satuan unit yang lain [2]. Dalam suatu proses Poisson periodik, bentuk fungsi intensitas pada periode sebelumnya dengan sesudahnya memiliki pola yang serupa. Oleh sebab itu, dalam kehidupan sehari-hari proses Poisson periodik berguna untuk memprediksi suatu kejadian pada periode berikutnya. Beberapa contoh penerapan proses Poisson dalam kehidupan sehari-hari dapat ditemukan pada [3]-[6].

Waktu tunggu kejadian ke- $m$ dari suatu proses Poisson adalah lama waktu sejak proses tersebut diamati sampai kejadian ke-m terjadi. Dalam kehidupan sehari-hari, waktu tunggu suatu kejadian proses Poisson sangat berguna, contohnya untuk memprediksi kedatangan pengunjung dalam suatu pusat servis sehingga memungkinkan sistem untuk mengetahui jam istirahat yang efisien. Waktu tunggu untuk kasus proses Poisson homogen telah diketahui memiliki sebaran eksponensial [7], sedangkan belum banyak informasi yang tersedia tentang sebaran waktu tunggu proses Poisson nonhomogen. Kajian terhadap waktu tunggu proses Poisson nonhomogen sangatlah luas, hasil penelitian yang sudah ada salah satunya mengenai proses Poisson periodik dengan tren linear [8], dan proses Poisson periodik dengan tren fungsi pangkat [9]. Beberapa penelitian terkait tentang proses Poisson periodik yang lainnya dapat ditemukan pada [10]-[13].

Sebaran dari peubah acak waktu tunggu proses Poisson periodik umumnya tidak diketahui, sehingga diperlukan penduga fungsi sebaran dan fungsi kepekatan peluang dari peubah acak tersebut. Tujuan dari penelitian ini adalah merumuskan penduga dan membuktikan kekonsistenan penduga fungsi sebaran dan fungsi kepekatan peluang waktu tunggu proses Poisson periodik.

Artikel ini disusun dalam 4 bagian, yaitu pendahuluan, metode penelitian, hasil, dan kesimpulan. Pada bagian hasil, rumus penduga ditulis pada sub bagian ke-2, beberapa lema teknis ditulis pada sub bagian ke-3, kekonsistenan penduga ditulis dalam bentuk teorema pada sub bagian ke-4, dan bukti matematis dari teorema tersebut ditulis pada sub bagian ke- 5 .

\section{Metode}

Fokus penelitian ini adalah pengembangan teori. Adapun langkah-langkah yang dilakukan dalam penelitian ini adalah sebagai berikut:

1. Studi pendahuluan

a. Mempelajari proses Poisson periodik,

b. Menggali landasan matematika untuk membuktikan teori baru.

2. Tahapan penelitian

a. Merumuskan penduga fungsi sebaran dan fungsi kepekatan peluang waktu tunggu proses Poisson periodik,

b. Membuktikan kekonsistenan penduga yang dikaji. 


\section{Hasil dan Pembahasan}

\subsection{Fungsi Sebaran dan Fungsi Kepekatan Peluang Waktu Tunggu Proses Poisson Periodik}

Misalkan proses $\{N(t), t \geq 0\}$ adalah proses Poisson periodik yang terdefinisi pada suatu ruang peluang $(\Omega, \mathcal{F}, \mathrm{P})$. Dengan kata lain, untuk setiap $s>0$, fungsi intensitas $\lambda$ dapat dituliskan sebagai berikut

$$
\lambda(s)=\lambda(s+k \tau),
$$

untuk setiap $s \geq 0$ dan $k \in \mathbb{N}$, dengan $\mathbb{N}$ menyatakan himpunan bilangan asli dan $\tau$ adalah panjang satu periode. Proses tersebut diamati pada suatu interval terbatas $[0, n]$. Untuk setiap $z>0$ dan untuk suatu bilangan bulat positif $m$, diperoleh fungsi sebaran $F_{T_{m}}$ dari waktu tunggu kejadian ke- $m T_{m}$ sebagai berikut:

$$
\begin{aligned}
F_{T_{m}}(z) & =\mathrm{P}\left(T_{m} \leq z\right) \\
& =\mathrm{P}(N[0, z] \geq m) \\
& =1-P(N[0, z] \leq m-1) \\
& =1-\left[\frac{e^{-\Lambda(\mathrm{z})}(\Lambda(\mathrm{z}))^{0}}{0 !}+\frac{e^{-\Lambda(\mathrm{z})}(\Lambda(\mathrm{z}))^{1}}{1 !}+\cdots+\frac{e^{-\Lambda(\mathrm{z})}(\Lambda(\mathrm{z}))^{m-1}}{(m-1) !}\right] \\
& =1-e^{-\Lambda(\mathrm{z})}\left[1+\Lambda(\mathrm{z})+\cdots+\frac{(\Lambda(\mathrm{z}))^{m-1}}{(m-1) !}\right]
\end{aligned}
$$

$\operatorname{dimana} \Lambda(\mathrm{z})=E(N[0, z])=\int_{0}^{z} \lambda(s) d s$.

Misalkan $z_{r}=z-\tau\left\lfloor\frac{z}{\tau}\right\rfloor$, dimana untuk suatu bilangan real $x,\lfloor x\rfloor$ menyatakan bilangan bulat terbesar yang kurang dari atau sama dengan $x$, maka untuk setiap $z>0$ diperoleh $z=z_{r}+\tau\left\lfloor\frac{z}{\tau}\right\rfloor$ dengan $0<z_{r}<\tau$. Dimisalkan $\theta=\tau^{-1} \int_{0}^{z} \lambda(s) d s$, yaitu intensitas global dari $N$. Untuk setiap $z>0, \Lambda(\mathrm{z})$ dapat ditulis sebagai berikut

$$
\left.\Lambda(\mathrm{z})=\int_{0}^{z} \lambda(s) d s=\int_{0}^{z_{r}} \lambda(s) d s+\int_{z_{r}}^{z} \lambda(s) d s=\Lambda\left(z_{r}\right)+\theta \tau \mid \frac{z}{\tau}\right\rfloor .
$$

dengan $\int_{0}^{z_{r}} \lambda(s) d s$ adalah integral dari fungsi intensitas untuk periode yang tidak penuh dengan panjang interval $z_{r}$ dan $\int_{z_{r}}^{z} \lambda(s) d s$ adalah integral dari fungsi intensitas untuk periode yang penuh sebanyak $\tau\left\lfloor\frac{z}{\tau} \mid\right.$ periode, sehingga dapat dirumuskan sebagai $\theta \tau\left|\frac{z}{\tau}\right|$. Untuk setiap $z>0$ dan untuk suatu bilangan bulat positif $m$, diperoleh fungsi kepekatan $f_{T_{m}}$ dari waktu tunggu $T_{m}$ sebagai berikut

$f_{T_{m}}(z)=\frac{d}{d z}\left(1-e^{-\Lambda(\mathrm{z})}\left[1+\Lambda(\mathrm{z})+\frac{(\Lambda(\mathrm{z}))^{2}}{2 !}+\cdots+\frac{(\Lambda(\mathrm{z}))^{m-1}}{(m-1) !}\right]\right)$ 
Penduga Konsisten dari Fungsi Sebaran dan Fungsi Kepekatan Peluang Waktu Tunggu ...

$$
\begin{aligned}
& =\lambda(\mathrm{z}) e^{-\Lambda(\mathrm{z})}\left[1+\Lambda(\mathrm{z})+\frac{(\Lambda(\mathrm{z}))^{2}}{2 !}+\cdots+\frac{(\Lambda(\mathrm{z}))^{m-1}}{(m-1) !}\right] \\
& -e^{-\Lambda(\mathrm{z})}\left[\lambda(z)+\frac{2 \Lambda(\mathrm{z}) \lambda(z)}{2 !}+\cdots+\lambda(z)(m-1) \frac{(\Lambda(\mathrm{z}))^{m-2}}{(m-1)(m-2) !}\right] \\
& =\lambda(\mathrm{z}) e^{-\Lambda(\mathrm{z})}\left[1+\Lambda(\mathrm{z})+\cdots+\frac{(\Lambda(\mathrm{z}))^{m-1}}{(m-1) !}\right]-\lambda(\mathrm{z}) e^{-\Lambda(\mathrm{z})}\left[1+\Lambda(\mathrm{z})+\cdots+\frac{(\Lambda(\mathrm{z}))^{m-2}}{(m-2) !}\right] \\
& =\lambda(\mathrm{z}) e^{-\Lambda(\mathrm{z})} \frac{(\Lambda(\mathrm{z}))^{m-1}}{(m-1) !} \text {. }
\end{aligned}
$$

\subsection{Rumus Penduga}

Penduga fungsi sebaran $F_{T_{m}}(z)$ dari proses Poisson periodik $N$ pada interval $[0, n]$ adalah

$$
\widehat{F}_{T_{m, n},}(z)=1-e^{-\widehat{\Lambda}_{n}(z)}\left(1+\hat{\Lambda}_{n}(z)+\cdots+\frac{\left(\hat{\Lambda}_{n}(z)\right)^{m-1}}{(m-1) !}\right)
$$

dengan

$$
\left.\hat{\Lambda}_{n}(z)=\hat{\Lambda}_{n}\left(z_{r}\right)+\hat{\theta}_{n} \tau \mid \frac{z}{\tau}\right\rfloor
$$

(cf. (3)) dimana

$$
\hat{\theta}_{n}=\frac{N\left[0, \tau n_{\tau}\right]}{\tau n_{\tau}}
$$

dan untuk $0<z_{r}<\tau$,

$$
\hat{\Lambda}_{n}\left(z_{r}\right)=\frac{1}{n_{\tau}} \sum_{k=0}^{n_{\tau}-1} N\left[k \tau, k \tau+z_{r}\right]
$$

dimana $n_{\tau}=\left\lfloor\frac{n}{\tau}\right\rfloor$ menyatakan bilangan bulat terbesar yang lebih kecil atau sama dengan $\frac{n}{\tau}$. Dengan kata lain, $n_{\tau}$ adalah banyaknya periode pada interval $[0, n]$.

Penduga fungsi kepekatan peluang $f_{T_{m}, n}$ pada suatu nilai $z$ adalah

$$
\hat{f}_{T_{m, n}}(z)=\hat{\lambda}_{n}(z) e^{-\widehat{\Lambda}_{n}(z)} \frac{\left(\hat{\Lambda}_{n}(z)\right)^{m-1}}{(m-1) !}
$$

(cf. (1) dan (4)) dimana $z>0, \hat{\lambda}_{n}(z)$ merupakan 


$$
\hat{\lambda}_{n}(z)=\frac{\tau}{n} \sum_{k=0}^{\infty} \frac{1}{2 h_{n}} N\left(\left[s+k \tau-h_{n}, s+k \tau+h_{n}\right] \cap[0, n]\right),
$$

yaitu kasus khusus dari penduga fungsi intensitas $\lambda$ tipe Kernel yang dikenalkan pada [10] dengan fungsi kernel $K=\frac{1}{2} \mathbf{I}_{[-1,1]}$. Statistik penduga sudah dijelaskan pada [11], dengan $h_{n}$ adalah barisan bilangan real positif sedemikian sehingga $h_{n} \downarrow 0$ ketika $n \rightarrow$ $\infty$ dan $\mathrm{K}$ menyatakan fungsi kernel $K: R \rightarrow[0, \infty)$ yang memenuhi sifat-sifat:

(K.1) K merupakan fungsi kepekatan peluang,

(K.2) K terbatas,

(K.3) K memiliki daerah definisi [-1,1],

(K.4) K kontinu, kecuali mungkin untuk beberapa interval terbatas.

Beberapa hasil penelitian yang terkait tentang estimasi fungsi intensitas dari proses Poisson periodik dapat ditemukan pada [14]-[24].

\subsection{Beberapa Lema Teknis}

Untuk membuktikan kekonsistenan penduga diperlukan lema-lema sebagai berikut:

Lema 1. Misalkan fungsi intensitas $\lambda$ memenuhi persamaan (1) dan terintegralkan lokal. Misalkan pula kernel $K$ memenuhi asumsi (K.1)-(K.4). Jika bandwidth $h_{n} \downarrow 0$ dan $n h_{n} \rightarrow \infty$ ketika $n \rightarrow \infty$ maka

$$
\hat{\lambda}_{n, K}(s) \stackrel{p}{\rightarrow} \lambda(s)
$$

ketika $n \rightarrow \infty$ asalkan $s$ adalah titik Lebesgue dari $\lambda$. Dengan kata lain, $\hat{\lambda}_{n, K}(s)$ adalah penduga konsisten untuk $\lambda(s)$. Bukti dapat dilihat pada [14].

Lema 2. Jika fungsi intensitas $\lambda$ memenuhi (1) dan terintegralkan lokal, maka

$$
\hat{\Lambda}_{n}\left(z_{r}\right) \stackrel{p}{\rightarrow} \Lambda\left(z_{r}\right)
$$

untuk $n \rightarrow \infty$. Dengan kata lain, $\hat{\Lambda}_{n}\left(z_{r}\right)$ adalah penduga konsisten untuk $\Lambda\left(z_{r}\right)$. Bukti dapat dilihat pada [19].

Proposisi 1. Misalkan fungsi intensitas memenuhi (1) dan terintegral lokal. Maka,

$$
\hat{\theta}_{n} \stackrel{p}{\rightarrow} \theta
$$

ketika $n \rightarrow \infty$. Dengan kata lain, $\hat{\theta}_{n}$ adalah penduga konsisten untuk $\theta$.

Dari (6), Lema 2 and Proposisi 1, kita mendapatkan Akibat 1.

Bukti Proposisi 1. Untuk membuktikan kekonsistenan penduga, kita cukup membuktikan bahwa

$$
E\left(\hat{\theta}_{n}\right) \rightarrow \theta
$$

dan 
Penduga Konsisten dari Fungsi Sebaran dan Fungsi Kepekatan Peluang Waktu Tunggu ...

$$
\operatorname{Var}\left(\hat{\theta}_{n}\right) \rightarrow 0
$$

saat $n \rightarrow \infty$.

Pertama-tama kita buktikan persamaan (11). Jelas bahwa,

$E\left(\hat{\theta}_{n}\right)=E\left(\frac{N\left[0, \tau n_{\tau}\right]}{\tau n_{\tau}}\right)=\frac{1}{\tau n_{\tau}} E\left(N\left[0, \tau n_{\tau}\right]\right)$

$=\frac{1}{\tau n_{\tau}} \int_{0}^{\tau n_{\tau}} \lambda(s) d s$

$=\frac{1}{\tau n_{\tau}}\left(\int_{0}^{\tau} \lambda(s) d s+\int_{\tau}^{2 \tau} \lambda(s) d s+\cdots+\int_{\tau\left(n_{\tau}-1\right)}^{\tau n_{\tau}} \lambda(s) d s\right)$

$=\frac{1}{\tau n_{\tau}}\left(n_{\tau} \int_{0}^{\tau} \lambda(s) d s\right)$

$=\frac{1}{\tau}\left(\int_{0}^{\tau} \lambda(s) d s\right)=\theta$.

Selanjutnya, kita buktikan persamaan (12). Jelas bahwa,

$\operatorname{Var}\left(\hat{\theta}_{n}\right)=\operatorname{var}\left(\frac{N\left[0, \tau n_{\tau}\right]}{\tau n_{\tau}}\right)=\left(\frac{1}{\tau n_{\tau}}\right)^{2} \operatorname{var}\left(N\left[0, \tau n_{\tau}\right]\right)$

$=\left(\frac{1}{\tau n_{\tau}}\right)^{2} E\left(N\left[0, \tau n_{\tau}\right]\right)$

$=\frac{1}{\tau n_{\tau}} \cdot \frac{1}{\tau n_{\tau}} E\left(N\left[0, \tau n_{\tau}\right]\right)$

$=\frac{1}{\tau n_{\tau}} E\left(\frac{N\left[0, \tau n_{\tau}\right]}{\tau n_{\tau}}\right)$

$=\frac{\theta}{\tau n_{\tau}} \rightarrow 0$

ketika $n \rightarrow \infty$. $\square$

Akibat 1. Misalkan fungsi intensitas memenuhi (1) dan terintegral lokal. Maka, untuk suatu $z>0$ diperoleh

$$
\hat{\Lambda}_{n}(z) \stackrel{p}{\rightarrow} \Lambda(\mathrm{z})
$$




\subsection{Kekonsistenan Penduga}

Syarat perlu agar sebuah penduga layak untuk digunakan adalah penduga tersebut harus konsisten. Hasil utama dari penelitian ini dituangkan pada dua teorema. Teorema 1 menjelaskan tentang kekonsistenan penduga fungsi sebaran $T_{m}$ dan Teorema 2 menjelaskan tentang kekonsistenan penduga fungsi kepekatan peluang $T_{m}$.

Teorema 1. Jika fungsi intensitas $\lambda$ memenuhi (1) dan terintegralkan lokal, maka untuk setiap $z>0$ dan setiap bilangan bulat positif $m$, diperoleh

$$
\widehat{F}_{T_{m, n}}(z) \stackrel{p}{\rightarrow} F_{T_{m}}(z)
$$

untuk $n \rightarrow \infty$.

Bukti. Untuk membuktikan (13), kita menggunakan persamaan (5) dan (2) sebagai berikut:

$$
\begin{aligned}
& \widehat{F}_{T_{m, n}}(z)-F_{T_{m}} \\
& =1-e^{-\widehat{\Lambda}_{n}(z)}\left(1+\hat{\Lambda}_{n}(z)+\cdots+\frac{\left(\hat{\Lambda}_{n}(z)\right)^{m-1}}{(m-1) !}\right) \\
& -\left(1-e^{-\Lambda(z)}\left(1+\Lambda(z)+\cdots+\frac{(\Lambda(z))^{m-1}}{(m-1) !}\right)\right) \\
& =e^{-\Lambda_{n}(z)}\left(1+\Lambda(z)+\cdots+\frac{(\Lambda(z))^{m-1}}{(m-1) !}\right)-e^{-\widehat{\Lambda}_{n}(z)}\left(1+\hat{\Lambda}_{n}(z)+\cdots+\frac{\left(\hat{\Lambda}_{n}(z)\right)^{m-1}}{(m-1) !}\right) \\
& =\left(e^{-\Lambda(z)}-e^{-\widehat{\Lambda}_{n}(z)}\right)\left(1+\Lambda(z)+\cdots+\frac{(\Lambda(z))^{m-1}}{(m-1) !}\right) \\
& -e^{-\widehat{\Lambda}_{n}(z)}\left(\left(\hat{\Lambda}_{n}(z)-\Lambda(z)\right)+\cdots\right. \\
& \left.+\left(\frac{\left(\hat{\Lambda}_{n}(z)\right)^{m-1}}{(m-1) !}-\frac{(\Lambda(z))^{m-1}}{(m-1) !}\right)\right) \text {. }
\end{aligned}
$$

Dengan ekspansi deret Taylor dan Akibat 1, diperoleh

$$
\begin{aligned}
& e^{-\Lambda(z)}-e^{-\widehat{\Lambda}_{n}(z)}=e^{-\Lambda(z)}\left(1-e^{-\left(\hat{\Lambda}_{n}(z)-\Lambda(z)\right)}\right) \\
& =e^{-\Lambda(z)}\left(1-\left(1-\left(\hat{\Lambda}_{n}(z)-\Lambda(z)\right)-\frac{\left(\hat{\Lambda}_{n}(z)-\Lambda(z)\right)^{2}}{2}-\frac{\left(\hat{\Lambda}_{n}(z)-\Lambda(z)\right)^{3}}{6}-\cdots\right)\right)
\end{aligned}
$$


Penduga Konsisten dari Fungsi Sebaran dan Fungsi Kepekatan Peluang Waktu Tunggu ...

$=e^{-\Lambda(z)}\left(\left(\hat{\Lambda}_{n}(z)-\Lambda(z)\right)+\frac{\left(\hat{\Lambda}_{n}(z)-\Lambda(z)\right)^{2}}{2}+\cdots\right)$

$=e^{-\Lambda(z)} o_{p}(1)$

$=o_{p}(1)$

saat $n \rightarrow \infty$. Karena $\left(1+\Lambda(z)+\cdots+\frac{(\Lambda(z))^{m-1}}{(m-1) !}\right) \leq e^{\Lambda(z)}=\mathcal{O}(1)$, untuk suatu $m \geq 1$, maka kita peroleh suku pertama pada persamaan (14) adalah $o_{p}(1)$ saat $n \rightarrow \infty$.

Untuk mengecek suku kedua pada persamaan (14), perhatikan bahwa untuk suatu bilangan asli $l$ diperoleh

$$
\left(\hat{\Lambda}_{n}(z)\right)^{l}-(\Lambda(z))^{l}=o_{p}(1)
$$

saat $n \rightarrow \infty$. Persamaan (15) dapat dibuktikan dengan induksi matematika. Pertama, jelas bahwa $\hat{\Lambda}_{n}(z)-\Lambda(z)=o_{p}(1)$ saat $n \rightarrow \infty$ dari Akibat 1 . Selanjutnya, kita asumsikan bahwa persamaan (20) benar untuk suatu $l=k>1$, maka diperoleh

$$
\begin{aligned}
& \left(\hat{\Lambda}_{n}(z)\right)^{k+1}-(\Lambda(z))^{k+1}=\hat{\Lambda}_{n}(z)\left(\hat{\Lambda}_{n}(z)\right)^{k}-\Lambda(z)(\Lambda(z))^{k} \\
& =\hat{\Lambda}_{n}(z)\left(\hat{\Lambda}_{n}(z)\right)^{k}-\hat{\Lambda}_{n}(z)(\Lambda(z))^{k}+\hat{\Lambda}_{n}(z)(\Lambda(z))^{k}-\Lambda(z)(\Lambda(z))^{k} \\
& =\hat{\Lambda}_{n}(z)\left(\left(\hat{\Lambda}_{n}(z)\right)^{k}-(\Lambda(z))^{k}\right)+(\Lambda(z))^{k}\left(\hat{\Lambda}_{n}(z)-\Lambda(z)\right) \\
& =\hat{\Lambda}_{n}(z) o_{p}(1)+(\Lambda(z))^{k} o_{p}(1)=o_{p}(1)
\end{aligned}
$$

ketika $n \rightarrow \infty$.

Akibatnya, untuk setiap $1 \leq l \leq m-1$ diperoleh

$$
\frac{(\Lambda(z))^{l}}{l !}-\frac{\left(\hat{\Lambda}_{n}(z)\right)^{l}}{l !}=\frac{1}{l !}\left((\Lambda(z))^{l}-\left(\hat{\Lambda}_{n}(z)\right)^{l}\right)=\frac{1}{l !} o_{p}(1)=o_{p}(1)
$$

Sehingga suku kedua pada persamaan (15) dapat ditulis sebagai

$$
\begin{aligned}
& e^{-\widehat{\Lambda}_{n}(z)}\left(\left(\hat{\Lambda}_{n}(z)-\Lambda(z)\right)+\cdots+\left(\frac{\left(\hat{\Lambda}_{n}(z)\right)^{m-1}}{(m-1) !}-\frac{(\Lambda(z))^{m-1}}{(m-1) !}\right)\right) \\
& =e^{-\widehat{\Lambda}_{n}(z)} \sum_{l=1}^{m-1}\left(\frac{\left(\hat{\Lambda}_{n}(z)\right)^{l}}{l !}-\frac{(\Lambda(z))^{l}}{l !}\right)
\end{aligned}
$$


$=e^{-\widehat{\Lambda}_{n}(z)}(m-1) o_{p}(1)$

$=o_{p}(1)$

ketika $n \rightarrow \infty$ karena $e^{-\widehat{\Lambda}_{n}(z)} \leq 1$ dengan peluang 1 .

Teorema 2. Misalkan fungsi intensitas $\lambda$ memenuhi (1) dan terintegralkan lokal. Jika $h_{n} \downarrow 0$ dan $n h_{n} \rightarrow \infty$ untuk $n \rightarrow \infty$ maka untuk setiap $z>0$ dan setiap bilangan bulat positif $m$, diperoleh

$$
\hat{f}_{T_{m, n}, n}(z) \stackrel{p}{\rightarrow} f_{T_{m}}(z)
$$

untuk $n \rightarrow \infty$.

Bukti. Perhatikan bahwa persamaan (16), juga dapat ditulis sebagai $\hat{f}_{T_{m, n}}(z) \stackrel{p}{\rightarrow} f_{T_{m}}(z)$ atau dengan kata lain, $\hat{\lambda}_{n}(z) e^{-\widehat{\Lambda}_{n}(z)} \frac{\left(\widehat{\Lambda}_{n}(z)\right)^{m-1}}{(m-1) !} \stackrel{p}{\rightarrow} \lambda(z) e^{-\Lambda_{n}(z)} \frac{(\Lambda(z))^{m-1}}{(m-1) !}$. Dari Lema 1, Akibat 1 , dan fakta bahwa $f(x)=e^{-x}$ merupakan fungsi kontinu, kita mendapatkan untuk suatu $z>0, \hat{\lambda}_{n}(z) e^{-\widehat{\Lambda}_{n}(z)} \stackrel{p}{\rightarrow} \lambda_{n}(z) e^{-\Lambda(z)}$ ketika $n \rightarrow \infty$.

Selanjutnya,dari persamaan (15) dengan mengubah $l$ dengan suatu bilangan bulat positif $m-1$, kita juga memperoleh $\frac{\left(\hat{\Lambda}_{n}(z)\right)^{m-1}}{(m-1) !}-\frac{(\Lambda(z))^{m-1}}{(m-1) !}=o_{p}(1)$, saat $n \rightarrow \infty$ atau dengan kata lain, $\frac{\left(\widehat{\Lambda}_{n}(z)\right)^{m-1}}{(m-1) !} \stackrel{p}{\rightarrow} \frac{(\Lambda(z))^{m-1}}{(m-1) !}$.

\section{Kesimpulan}

Penduga konsisten bagi fungsi sebaran dan fungsi kepekatan peluang waktu tunggu proses Poisson periodik berturut-turut adalah

$$
\widehat{F}_{T_{m, n}, n}(z)=1-e^{-\widehat{\Lambda}_{n}(z)}\left(1+\hat{\Lambda}_{n}(z)+\cdots+\frac{\left(\widehat{\Lambda}_{n}(z)\right)^{m-1}}{(m-1) !}\right)
$$

dan

$$
\hat{f}_{T_{m, n} n}(z)=\hat{\lambda}_{n, K}(z) e^{-\widehat{\Lambda}_{n}(z)} \frac{\left(\hat{\Lambda}_{n}(z)\right)^{m-1}}{(m-1) !},
$$

dengan

$$
\left.\hat{\Lambda}_{n}(z)=\hat{\Lambda}_{n}\left(z_{r}\right)+\hat{\theta}_{n} \tau \mid \frac{Z}{\tau}\right\rfloor,
$$

dan

$$
\hat{\theta}_{n}=\frac{N\left[0, \tau n_{\tau}\right]}{\tau n_{\tau}}
$$




$$
\begin{gathered}
\hat{\Lambda}_{n}\left(z_{r}\right)=\frac{1}{n_{\tau}} \sum_{k=0}^{n_{\tau}-1} N\left[k \tau, k \tau+z_{r}\right], \\
\hat{\lambda}_{n, K}(z)=\frac{\tau}{n} \sum_{k=-\infty}^{\infty} \frac{1}{h_{n}} \int_{0}^{n} K\left(\frac{x-(z+k \tau)}{h_{n}}\right) N(d x),
\end{gathered}
$$

dimana $n_{\tau}$ adalah bilangan bulat terbesar yang lebih kecil atau sama dengan $\frac{n}{\tau^{\prime}} K$ adalah suatu kernel dan $h_{n}$ adalah barisan bilangan real positif yang konvergen ke nol, yaitu $h_{n} \downarrow 0$ untuk $n \rightarrow \infty$ dan $n h_{n} \rightarrow \infty$. Penelitian ini masih dapat dilanjutkan dengan menambahkan simulasi dan studi lanjut mengenai sifat-sifat statistik penduga yang lainnya, seperti sebaran asimtotik penduga. Contoh simulasi terkait proses Poisson nonhomogen dapat ditemukan pada [25] dan [26].

\section{Referensi}

[1] R.G. Gallager, Discrete Stochastic Processes. New York: Springer Science+Business Med., 1996.

[2] T.A. Walls, J.L. Schafer, Models for Intensive Longitudinal Data. New York: Oxford Univ. Pr., 2006.

[3] T. Ngailo, N. Shaban, J. Reuder, E.C. Rutalebwa, and I. Mugume, "NonHomogeneous Poisson Process Modelling of Seasonal Extreme Rainfall Events in Tanzania," Int. J. Sci. Res., vol. 5, no. 10, pp. 1858-1868, Oct. 2016.

[4] D. Vere-Jones and T. Ozaki, "Some examples of statistical estimation applied to earthquake data," Ann. Inst. Stat. Math., vol. 34, no. 1, pp. 189-207, 1982, doi: 10.1007/BF02481022.

[5] J.J. Brey, J. Casado-Pascual, and B. Sánchez, "Resonant behavior of a Poisson process driven by a periodic signal," Phys. Rev. E., vol. 52, no. 6, pp. 6071-6081, Dec. 1995, doi: 10.1103/PhysRevE.52.6071.

[6] T. Rolski, "Relationships between characteristics in periodic Poisson queues," Queueing Syst., vol. 4, no. 1, pp. 17-26, 1989, doi: 10.1007/BF01150853.

[7] S.M. Ross, Introduction to Probability Models, 9 Edition. Orlando: Academic Press Inc., 2010.

[8] I.W. Mangku, "Consistent estimation of the distribution function and the density of waiting time of a cyclic Poisson process with linear trend," Far East J. of Theo. Stat., vol. 33, no. 1, pp. 81-91, 2010.

[9] D.F. Putera, "Kekonsistenan penduga dari fungsi sebaran dan fungsi kepekatan peluang waktu tunggu proses Poisson periodik dengan tren fungsi pangkat," Institut Pertanian Bogor, 2012.

[10] R. Helmers and I.W. Mangku, "Predicting a cyclic Poisson process," Annals Inst. of Stat. Math., vol. 6, no. 4, pp. 1261-1279, 2012, doi:10.1007/s10463-012-0349-x.

[11] S. Browne and U. Yechiali, “Dynamic Priority Rules for Cyclic-Type Queues," Adv. Appl. Probab., vol. 21, no. 2, pp. 432-450, May 1989, doi: 10.2307/1427168. 
[12] B.N. Dimitrov, V.V. Rykov, and Z.L. Krougly, "Periodic Poisson Processes and Almost-lack-of-memory Distributions," Autom. Remote Control, vol. 65, no. 10, pp. 1597-1610, 2004, doi: 10.1023/B:AURC.0000044269.32890.3e.

[13] S.G. Henderson, "Estimation for nonhomogeneous Poisson processes from aggregated data," Oper. Res. Lett., vol. 31, no. 5, pp. 375-382, 2003, doi: https://doi.org/10.1016/S0167-6377(03)00027-0.

[14] R. Helmers, I.W. Mangku, and R. Zitikis, "Consistent estimation of the intensity function of a cyclic Poisson process," J. Multivar. Anal., vol. 84, no. 1, pp. 19-39, 2003, doi: 10.1016/S0047-259X(02)00008-8.

[15] R. Helmers, I.W. Mangku, and R. Zitikis, "Statistical properties of a kernel-type estimator of the intensity function of a cyclic Poisson process," J. of Multivar. Anal., vol. 92, no. 1, pp. 1-23, 2005, doi: 10.1016/S0047-259X(03)00082-4.

[16] W. Erliana, I.W. Mangku, and H. Sumarno, "Estimating the intensity obtained as the product of a periodic function with the power function trend of a nonhomogeneous Poisson process," Far East J. of Math. Sci., vol. 90, no. 2, pp. 163-172, 2014.

[17] R. Helmers and I.W. Mangku, "Estimating the intensity of a cyclic Poisson process in the presence of linear trend," Annals Inst. of Stat.l Math., vol. 61, no. 3, pp. 599628, 2009, doi: 10.1007/s10463-007-0160-2.

[18] Y. I. Ingster and Y. A. Kutoyants, "Nonparametric hypothesis testing for intensity of the poisson process," Math. Methods Stat., vol. 16, no. 3, pp. 217-245, 2007, doi: 10.3103/S1066530707030039.

[19] I.W. Mangku, "Consistent estimation of the distribution function and the density of waiting time of a cyclic Poisson process with linear trend," Far East J. of Theo. Stat., vol. 33, no. 1, pp. 81-91, 2010.

[20] I.W. Mangku, R. Budiarti, Taslim, and Casman, "Estimating the intensity obtained as the product of a periodic function with the quadratic trend of a nonhomogeneous Poisson process," Far East J. of Math. Sci., vol. 82, no. 1, pp. 33-44, 2013.

[21] I.W. Mangku, Siswadi, and R. Budiarti, "Consistency of a kernel-type estimator of the intensity of the cyclic Poisson process with the linear trend," J. Indones. Math. Soc., vol. 15, no. 1, 2012, doi: 10.22342/jims.15.1.42.37-48.

[22] I.W. Mangku, Siswadi, and R. Budiarti 2011, "Asymptotic approximations to the bias and variance of a kernel-type estimator of the intensity of the cyclic Poisson process with the linear trend," J. of the Indones. Math. Soc., vol. 17, no. 1, pp. 1-9, 2011.

[23] I. Maulidi, I.W. Mangku, and H. Sumarno, "Strong consistency of a kernel-type estimator for the intensity obtained as the product of a periodic function with the power function trend of a non-homogeneous Poisson process," Br. J. Appl. Sci. Technol., vol. 9, no. 4, pp. 383-387, 2015, doi: 10.9734/bjast/2015/17391.

[24] I. W. Mangku, "Estimating the intensity of a cyclic Poisson process in the presence of additive and multiplicative linear trend," J. Phys. Conf. Ser., vol. 893, p. 012023, Oct. 2017, doi: 10.1088/1742-6596/893/1/012023. 
[25] K. P. White, "Simulating a nonstationary Poisson process using bivariate thinning: the case of 'typical weekday' arrivals at a consumer electronics store," in WSC'99. 1999 Winter Simulation Conference Proceedings. "Simulation - A Bridge to the Future" (Cat. No.99CH37038), 1999, vol. 1, pp. 458-461, doi: 10.1109/WSC.1999.823109.

[26] L. E. Morgan, B. L. Nelson, A. C. Titman, and D. J. Worthington, “A Spline-Based Method for Modelling and Generating A Nonhomogeneous Poisson Process," in 2019 Winter Simulation Conference (WSC), 2019, pp. 356-367, doi: 10.1109/WSC40007.2019.9004867.

This article is an open-access article distributed under the terms and conditions of the Creative Commons Attribution-NonCommercial 4.0 International License. Editorial of JJoM: Department of Mathematics, Universitas Negeri Gorontalo, Jln. Prof. Dr. Ing. B.J. Habibie, Moutong, Tilongkabila, Kabupaten Bone Bolango, Provinsi Gorontalo 96119, Indonesia. 